\title{
Highly efficient and thermally stable NLO organic materials based on pyrrole and thiophene heterocycles
}

\author{
M. Cidália R. Castro ${ }^{\mathrm{a}}$, A. Maurício C. Fonseca ${ }^{\mathrm{a}}$, M. Belsley ${ }^{\mathrm{b}}$, M. Manuela M. Raposo*a \\ ${ }^{a}$ Center of Chemistry, University of Minho, Campus of Gualtar, 4710-057 Braga, Portugal \\ ${ }^{\mathrm{b}}$ Center of Physics, University of Minho, Campus of Gualtar, 4710-057 Braga, Portugal
}

\begin{abstract}
A series of novel donor-acceptor chromophores designed to have good second order nonlinear optical responses has been synthesized and characterized. This series of compounds was designed to explore the consequence of using different electron accepting moieties which were linked through an arylthiophene bridge to a pyrrole heterocycle that plays the role of an auxiliary donor group. These new push-pull chromophores have been extensively characterized using cyclic voltammetry, thermogravimetric analysis and hyper-Rayleigh scattering (HRS) in solution. The measured molecular first hyperpolarizabilities and the observed electrochemical behavior showed that they were very sensitive to the acceptor strength of the acceptor moieties. Moreover, the combination of their good nonlinearity and high thermal stability make them good candidates for potential device applications.
\end{abstract}

Keywords: nonlinear optics (NLO), hyper-Rayleigh scattering (HRS) technique, push-pull heterocyclic systems, redox potentials, thermal stability, auxiliary donor heterocycle, pyrrole, thiophene.

\section{INTRODUCTION}

Over the last two decades there has been an intense research effort aimed at improving the nonlinear optical response of push-pull type organic chromophores, motivated by their strong potential to make fundamental improvements in organic modern communication technology, e.g. ultrafast image-processing, optical data processing, transmission, and storage. In particular attention has recently been focused on optimizing the second-order nonlinear optical (NLO) response of the ground-state polarization of molecules by using different combinations of electron donor (D), electron acceptor (A), and $\pi$-conjugated bridges, ${ }^{1-2}$ known as D- $\pi$-A NLO chromophores. A combination of synthetic innovations reinforced by theoretical chemical calculations and confirmed by structural and optical characterizations has shown that the usage of easily delocalized five-membered heteroaromatic rings (usually thiophene, furan and thiazole) instead of benzene ring results in an enhanced molecular nonlinear response as quantified through the first molecular hyperpolarizability, $\beta .^{3-4}$ Although a large variety of donor, acceptor and spacer groups have been used for the design of NLO chromophores, the use of pyrrole heterocycle as conjugated bridge and/or as a strong donor moiety has rarely appeared in the NLO literature ${ }^{5-7}$ probably due to the difficulty of their synthesis. Recently we were able to overcome these difficulties and reported on the interesting electrochemical and solvatochromic properties and the first hyperpolarizabilities of pyrrolecontaining NLO chromophores with potential application as nonlinear optical compounds. ${ }^{8-12}$ We were therefore motivated to extend these studies and explore the potential of a novel series 1-(4-(thiophen-2-yl)phenyl)- $1 H$-pyrroles 1 as efficient push-pull systems bearing pyrrole as donor group and dicyanovinyl, rhodanine, thiobarbituric acid and indanonedicyanovinyl as acceptor moieties linked through an arylthiophene spacer.

\section{EXPERIMENTAL TECHNIQUE OF HYPER-RAYLEIGH SCATTERING}

\subsection{Measurement}

Hyper-Rayleigh scattering was used to measure the first hyperpolarizability $\beta$ of response of the molecules studied. The experimental set-up for hyper-Rayleigh measurements is similar to the one presented by Clays et al. ${ }^{13-14}$ (Fig. 1). Particular care was taken to avoid common pitfalls with this method that can lead to erroneous values for the hyperpolarizability. 
The incident laser beam came from a Q-switched Nd:YAG laser operating at a $10 \mathrm{~Hz}$ repetition rate with approximately $10 \mathrm{~mJ}$ of energy per pulse and a pulse duration (FWHM) close to $12 \mathrm{~ns}$ at the fundamental wavelength of $1064 \mathrm{~nm}$. The incident power could be varied using a combination of a half wave-plate and Glan polarizer. The incident beam was weakly focused (beam diameter $\sim 0.5 \mathrm{~mm}$ ) into the solution contained in a $5 \mathrm{~cm}$ long cuvette. With this cuvette length we are able to aperture only the central region and thereby avoid detecting second harmonic signal from the cell windows.

The hyper- Rayleigh signal was collected at right angles to the incident beam and collimated using a high numerical aperture lens (0.8 N.A.). To detect only light emitted near $532 \mathrm{~nm}$ the signal passed first through an infrared blocking filter then through a narrow band interference filter centred at the second harmonic wavelength before being detected by a photomultiplier (Hamamatsu model H9305-04). The current pulse from the photomultiplier was integrated using a Stanford Research Systems gated box-car integrator (model SR250) with a 25 ns gate centred on the temporal position of the incident laser pulse. The hyper-Rayleigh signal was normalized at each pulse using the second harmonic signal from a $1 \mathrm{~mm}$ quartz plate to compensate for fluctuations in the temporal profile of the laser pulses due to longitudinal mode beating.

Dioxane was used as a solvent, and the $\beta$ values were calibrated using a reference solution of $p$-nitroaniline ( $p$ NA) ${ }^{15-16}$ also dissolved in dioxane at a concentration of $1 \times 10^{-2} \mathrm{~mol} \mathrm{dm}^{-3}$ (external reference method). The hyperpolarizability of $p$ NA dissolved in dioxane is known from EFISH measurements carried out at the same fundamental wavelength. The concentrations of the solutions under study were chosen so that the corresponding hyper-Rayleigh signals fell well within the dynamic range of both the photomultiplier and the box-car integrator. All solutions were filtered ( $0.2 \mu \mathrm{m}$ porosity) to avoid spurious signals from suspended impurities.
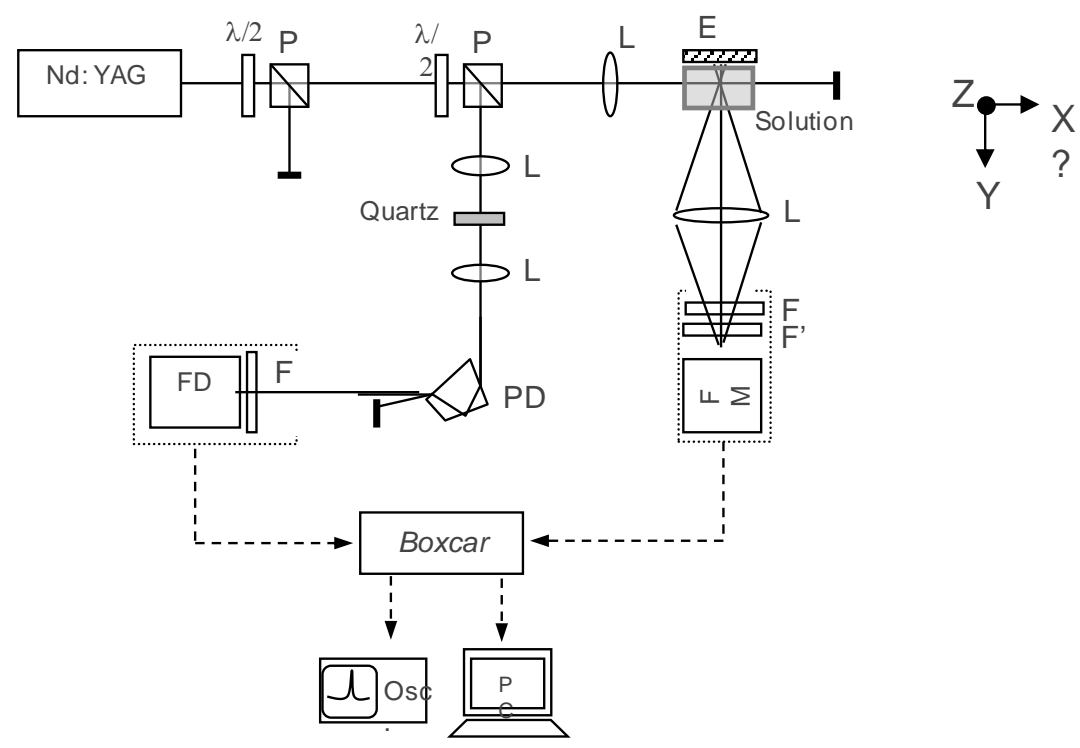

Figure 1. Scheme of assembly for hyper-Rayleigh scattering measurements. $\mathrm{P}=$ polarizer, $\lambda / 2=$ half-waveplate, $\mathrm{L}=$ lens, $\mathrm{E}=$ mirror, $\mathrm{PD}=$ pellin broca disperser prism, $\mathrm{F}^{\prime}=$ infrared cutoff filter $(\mathrm{KG} 3) \mathrm{F}=$ narrowband interference filter, $\mathrm{FD}=$ photodetector, $\mathrm{FM}=$ photomultiplier.

\subsection{Calculations}

The small hyper Rayleigh signal that arises from dioxane was taken into account according to the equation 1

$$
I_{2 \omega}=G\left(N_{\text {solvent }}\left\langle\beta_{\text {solvent }}^{2}\right\rangle+N_{\text {solute }}\left\langle\beta_{\text {solute }}^{2}\right\rangle\right) I_{\omega}^{2}
$$

where the factor $\mathrm{G}$ is an instrumental factor that takes into account the detection efficiency (including geometrical factors and linear absorption or scattering of the second harmonic light on its way to the detector) and local field corrections. 
We took especial care to avoid reporting artificially high hyperpolarizibilities due to a possible contamination of the hyper Rayleigh signal by molecular fluorescence near $532 \mathrm{~nm}$. Measurements were carried out using two different interference filters with different transmission pass bands centred near the second harmonic at $532 \mathrm{~nm}$. The transmission band of the narrower filter (CVI model F1.5-532-4) was $1.66 \mathrm{~nm}$ (full width at half maximum) with a transmission of $47.6 \%$ at the second harmonic, while the corresponding values for the wider filter (CVI model F03-532-4) were 3.31 nm, with a transmission of $63.5 \%$ at the second harmonic. The transmission of each filter at the second harmonic wavelength was carefully determined using a crystalline quartz sample. We assume that any possible fluorescence emitted from the solutions is essentially constant over the transmission of both interference filters. Then by comparing the signals obtained with the two different filters we can determine the relative contributions of the hyper-Rayleigh and possible fluorescence signals. The relevant equations (2 and 3) are:

$$
S_{N B}^{2 \omega}=\left(\frac{S_{N B} A_{W B}-S_{W B} A_{N B}}{T_{N B} A_{W B}-T_{W B} A_{N B}}\right) T_{N B}
$$

and

$$
S_{N B}^{F}=\left(\frac{S_{L B} T_{N B}-S_{N B} T_{L B}}{T_{N B} A_{W B}-T_{W B} A_{N B}}\right) A_{N B}
$$

Here $S_{N B}^{2 \omega}$ is the hyper-Rayleigh scattering contribution to the signal, i.e. the signal that would have been measured using the "narrow" band filter if there were no fluorescence present. The fluorescence contribution to the signal measured using the narrow band interference filter is $S_{N B}^{F}$. The signals $S_{N B}$ and $S_{W B}$ are the actual signals measured (after correction for the solvent contribution) using the "narrow" (CVI model F1.5-532-4) and "wide" (CVI model F03-532-4) band interference filters. The transmissions $T_{N B}$ and $T_{W B}$ are respectively the transmission of the "narrow" and "wide" band interference filters at the second harmonic wavelength (47.6\% and 63.5\%), $A_{N B}$ and $A_{W B}$ represent the area under the respective filter's transmission curve. The respective transmission curves were obtained using a dual-beam spectrophotometer with slits adjusted to give $0.1 \mathrm{~nm}$ resolution. We obtained values of $1.29 \mathrm{~nm}$ and $2.18 \mathrm{~nm}$ for $A_{N B}$ and $A_{W B}$ respectively. These values allow us to confidently characterize the first molecular hyperpolarizabilities even when the multi-photon induced fluorescence leads to a contamination of the measured signal by as much as $60 \%$.

After determining the amount of signal due solely to hyper-Rayleigh scattering by applying the above procedure the hyperpolarizability of each compound was estimated using the following expression,

$$
\beta=\beta_{p N a} \sqrt{\frac{S_{n b}^{2 \omega}}{S_{p N a}^{2 \omega}} \frac{N_{p N a}}{N_{c h r o m}}} .
$$

Here $N_{\text {chom }}$ and $N_{\mathrm{pNA}}$ are respectively the molar densities of the chromophore and $p$-nitroaniline solutions. In using this expression we assume, as is typical, that the hyperpolarizability tensor is dominated by a single longitudinal element. This is the case for the reference molecule, $p$ NA with a value of $\beta_{z z z}=16.9 \times 10^{-30}$ esu as measured using the EFISH technique. $^{15-16}$

\section{RESULTS}

\subsection{Synthesis}

A series of 1-(4-(thiophen-2-yl)phenyl)-1H-pyrroles 1b-e were synthesized in moderate to good yields by Knoevenagel reaction between formyl-pyrrole $1 \mathbf{a}$ and methylene active compounds in ethanol at reflux, in the presence of a catalytic amount of piperidine (Fig. 2, Table 1). The novel NLO-chromophores consists of several derivatives based on pyrrole 
heterocycle as the electron donor group which are connected via an arylthiophene spacer to formyl, dicyanovinyl, rhodanine, thiobarbituric acid and 2-(3-oxo-2,3-dihydroinden-1-ylidene)malononitrile acceptor groups.

The novel chromophores were characterized through the usual spectroscopic techniques. The details of the synthesis and the full characterization of compounds 1 will be described elsewhere.<smiles>O=Cc1ccc(-c2ccc(-n3cccc3)cc2)s1</smiles>

$1 \mathbf{a}$<smiles>CCN1C(=O)C(=Cc2ccc(-c3ccc(-n4cccc4)cc3)s2)C(=O)N(CC)C1=S</smiles><smiles>N#CC(C#N)=Cc1ccc(-c2ccc(-n3cccc3)cc2)s1</smiles>

$1 \mathrm{~b}$<smiles>O=C1NC(=S)C/C1=C\c1ccc(-c2ccc(-n3cccc3)cc2)s1</smiles>

$1 \mathrm{c}$

Figure 2. Chemical structures of the push-pull chromophores investigated: 1a 5-(4-(1H-pyrrol-1-yl)phenyl)thiophene-2-carbaldehyde);

1b 2-((5-(4-(1H-pyrrol-1-yl)phenyl)thiophen-2-yl)methylene)malononitrile); 1c 3-((5-(4-(1H-pyrrol-1-yl)phenyl)thiophen-2-

yl)methylene)-5-thioxopyrrolidin-2-one); 1d 5-((5-(4-(1H-pyrrol-1-yl)phenyl)thiophen-2-yl)methylene)-1,3-diethyl-dihydro-2thioxopyrimidine-4,6(1H,5H)-dione and 1e 2-((Z)-2-((5-(4-(1H-pyrrol-1-yl)phenyl)thiophen-2-yl)methylene)-1,2-dihydro-1oxoinden-3-ylidene)malononitrile.

Table 1. Yields, IR and $\mathrm{T}_{d}$ data for 1-(4-(thiophen-2-yl)phenyl)-1H-pyrroles 1

\begin{tabular}{|cccc|}
\hline Pyrrole & $\begin{array}{c}\text { Yield } \\
(\%)\end{array}$ & $\begin{array}{c}v^{\mathrm{a}} \\
\left(\mathrm{cm}^{-1}\right)\end{array}$ & $\begin{array}{c}\mathrm{T}_{d}{ }^{\mathrm{c}} \\
\left({ }^{\mathrm{o}} \mathrm{C}\right)\end{array}$ \\
\hline 1a & 41 & $1648(\mathrm{C}=\mathrm{O})^{\mathrm{b}}$ & 199 \\
& & $2221(\mathrm{C}=\mathrm{N})$ & 277 \\
& 65 & $1698(\mathrm{C}=\mathrm{O})$ & - \\
& & $1580(\mathrm{C}=\mathrm{S})$ & \\
& 37 & $1462(\mathrm{~N}-\mathrm{H})$ & \\
& & $1684(\mathrm{C}=\mathrm{O})$ & 270 \\
& & $1461(\mathrm{C}=\mathrm{S})$ & \\
& 65 & $1698(\mathrm{C}=\mathrm{O})$ & 239 \\
& & $2214(\mathrm{C}=\mathrm{N})$ & \\
\hline
\end{tabular}

${ }^{a}$ The IR spectra were obtained in Nujol.

${ }^{\mathrm{b}}$ The IR spectra were obtained in liquid film $\left(\mathrm{CHCl}_{3}\right)$.

${ }^{c}$ Decomposition temperature $\left(\mathrm{T}_{d}\right)$ measured at a heating rate of $20{ }^{\circ} \mathrm{C} \mathrm{min}^{-1}$ under a nitrogen atmosphere, obtained by thermogravimetric analysis (TGA). 


\subsection{Redox properties}

The redox properties of pyrroles 1a-e were studied by cyclic voltammetry in DMF containing tetrabutylammonium tetrafluoroborate $(0.10 \mathrm{M})$ as the supporting electrolyte. These studies were performed using a potentiostat/galvanostat (AUTOLAB /PSTAT 12) with the low current module ECD from ECO-CHEMIE and the data analysis processed by the General Purpose Electrochemical System software package also from ECO-CHEMIE. Three electrode-two compartment cells equipped with vitreous carbon-disc working electrodes, a platinum-wire secondary electrode and a silver-wire pseudo-reference electrode were employed for cyclic voltammetric measurements. The concentration of the compounds were $1 \mathrm{mmol} \mathrm{dm}^{-3}$ and $0.1 \mathrm{~mol} \mathrm{dm}^{-3}\left[\mathrm{NBu}_{4}\right]\left[\mathrm{BF}_{4}\right]$ was used as the supporting electrolyte in dry $N, N$-dimethylformamide solvent. The potential is measured with respect to ferrocinium/ferrocene as an internal standard.

The cyclic voltammetry study which was performed at different scan rates and potential ranges enabled the establishment of reversible and irreversible electrode processes. Table 2 lists the reduction and oxidation onsets and the electrochemical band gap values. On the basis of these potentials values, we estimated the HOMO and LUMO energy levels according as described from the potentials of the anodic and cathodic processes. ${ }^{17-18}$

All compounds displayed one irreversible oxidation process under the experimental conditions which can be attributed to the formation of radical cation of the pyrrole ring. The variation of the peak potential for oxidation of the pyrrole moiety reflects the electronic strength of the terminal electron acceptor group substituted in the thiophene ring. All compounds exhibit two reductions processes except compound 1c functionalized with a rhodanine acceptor moiety. These potentials are strongly influenced by the electronic nature of the acceptor group linked to the thiophene ring where the reduction process occurs (Fig. 3).,12

Table 2. Electrochemical data for coumpounds 1a-e.

\begin{tabular}{|c|c|c|c|c|c|c|c|}
\hline \multirow{2}{*}{ Pyrrole } & \multicolumn{3}{|c|}{ Reduction $^{\mathrm{a}}$} & \multirow{2}{*}{$\begin{array}{l}\text { Oxidation }^{\mathrm{a}} \\
{ }^{1} \mathrm{E}_{\mathrm{pa}}(\mathrm{V})\end{array}$} & \multirow{2}{*}{$\begin{array}{c}-\mathrm{E}_{\text {номо }}{ }^{\mathrm{c}} \\
(\mathrm{eV})\end{array}$} & \multirow{2}{*}{$\begin{array}{c}-E_{\text {LUMo }}{ }^{c} \\
(e V)\end{array}$} & \multirow{2}{*}{$\begin{array}{c}\text { Band gap }^{\mathrm{d}} \\
(\mathrm{eV})\end{array}$} \\
\hline & $-{ }^{1} \mathrm{E}_{\mathrm{pc}}(\mathrm{V})$ & $\Delta \mathrm{E}^{\mathrm{b}}(\mathrm{mV})$ & $-{ }^{2} \mathrm{E}_{\mathrm{pc}}(\mathrm{V})$ & & & & \\
\hline $1 \mathrm{a}$ & 2.06 & 81 & 2.70 & 0.92 & 5.31 & 2.33 & 2.98 \\
\hline $1 b$ & 1.41 & - & 2.91 & 0.91 & 5.30 & 2.98 & 2.32 \\
\hline $1 c$ & 2.01 & - & - & 0.85 & 5.24 & 2.38 & 2.86 \\
\hline 1d & 1.22 & - & 2.19 & 0.98 & 5.37 & 3.17 & 2.20 \\
\hline $1 \mathrm{e}$ & 1.96 & 90 & 2.17 & 1.04 & 5.43 & 2.43 & 3.00 \\
\hline
\end{tabular}

${ }^{a}$ Measurements made in dry DMF containing $1.0 \mathrm{mM}$ in each compounds and $0.10 \mathrm{M}\left[\mathrm{NBu}_{4}\right]\left[\mathrm{BF}_{4}\right]$ as base electrolyte at a carbon working electrode with a scan rate of $0.1 \mathrm{~V} \mathrm{~s}^{-1}$. All $\mathrm{E}$ values are quoted in volts $v s$ the ferrocinium/ferrocene - couple. $E_{\mathrm{pc}}$ and $E_{\mathrm{pa}}$ correspond to the cathodic and anodic peak potentials, respectively;

${ }^{\mathrm{b}} \Delta \mathrm{E}=\left|\mathrm{E}_{\text {red }}-\mathrm{E}_{\mathrm{ox}}\right|$

${ }^{\mathrm{c}} \mathrm{E}_{\mathrm{HOMO}}=-\left(4.39+\mathrm{E}_{\mathrm{ox}}\right)(\mathrm{eV})$ and $\mathrm{E}_{\mathrm{LUMO}}=-\left(\mathrm{E}_{\mathrm{red}}+4.39\right)(\mathrm{eV})$.

${ }^{\mathrm{d}}$ Calculated form the difference between the onset potentials for oxidation and reduction.

\subsection{Linear and nonlinear optical properties of the chromophores}

The studied chromophores showed good solubility in common polar and non-polar organic solvents such as dioxane and DMF. The extinction coefficients $(\varepsilon)$ in dioxane and wavelength maxima $\lambda_{\max }$ of compounds 1a-e in dioxane were obtained using a Shimadzu UV/2501PC spectrophotometer and are summarized in Table 3. The electronic absorption spectra of the chromophores in dioxane solutions $\left(10^{-4} \mathrm{M}\right)$ showed an intense lowest energy charge-transfer (CT) absorption band in the UV-visible region. The position of this band was strongly influenced by the electronic nature of the acceptor moiety. The absorption maxima $\left(\lambda_{\max }\right)$ of pyrrole-based chromophores $\mathbf{1 a - e}$, in dioxane are located at the 
range of 348 to $510 \mathrm{~nm}$. As observed earlier for other pyrrole push-pull systems, a bathochromic shift in the UV-Vis. spectra is observed when stronger acceptor groups are linked to the heterocyclic system. ${ }^{8-12,19-20}$ As a result the substitution of a formyl group for a 2-(3-oxo-2,3-dihydroinden-1-ylidene)malononitrile moiety leads to a red shift of 170 $\mathrm{nm}$ from $348 \mathrm{~nm}$ (1a) to $510 \mathrm{~nm}$ (1e). Within the series 1a-e the CT bands moves to lower energy as the electron accepting ability of the acceptor moiety increases, in the order $\mathrm{CHO}<$ dicyanovinyl $<$ rhodanine $<$ thiobarbituric acid $<$ 2-(3-oxo-2,3-dihydroinden-1-ylidene)malononitrile (Fig. 4).

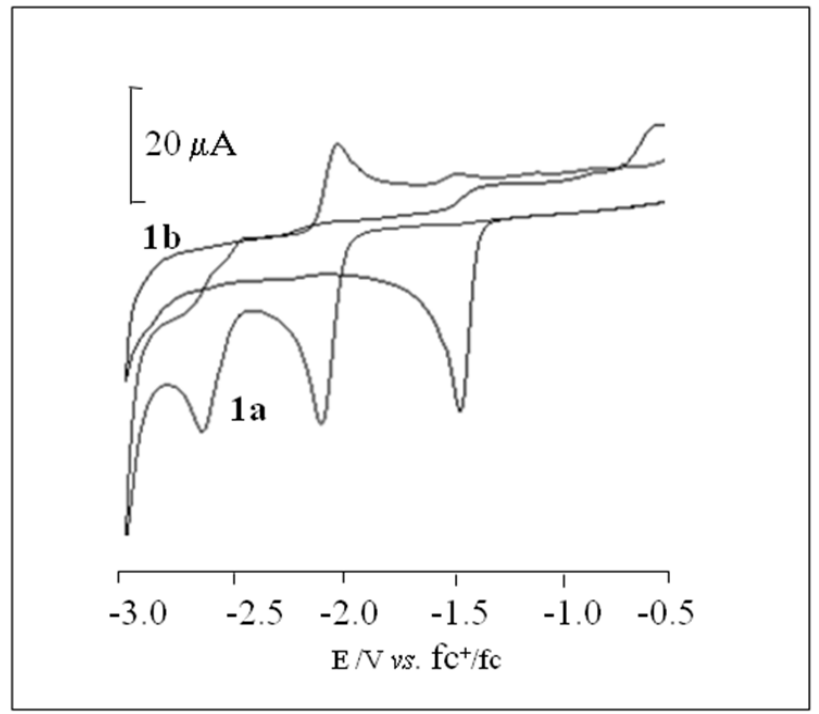

Figure 3. Cyclic voltammograms of compound $\mathbf{1 a}$ and $\mathbf{1 b}\left(1.0 \times 10^{-3} \mathrm{~mol} \mathrm{dm}^{-3}\right)$ in DMF, $0.1 \mathrm{~mol} \mathrm{dm}^{-3}\left[\mathrm{NBu}_{4}\right]\left[\mathrm{BF}_{4}\right]$ at a vitreous carbon electrode between $-0.50 \mathrm{~V}$ and $-3.0 \mathrm{~V} v s$. $\mathrm{fc}^{+} / \mathrm{fc}$, scan rate $0.1 \mathrm{Vs}^{-1}$.

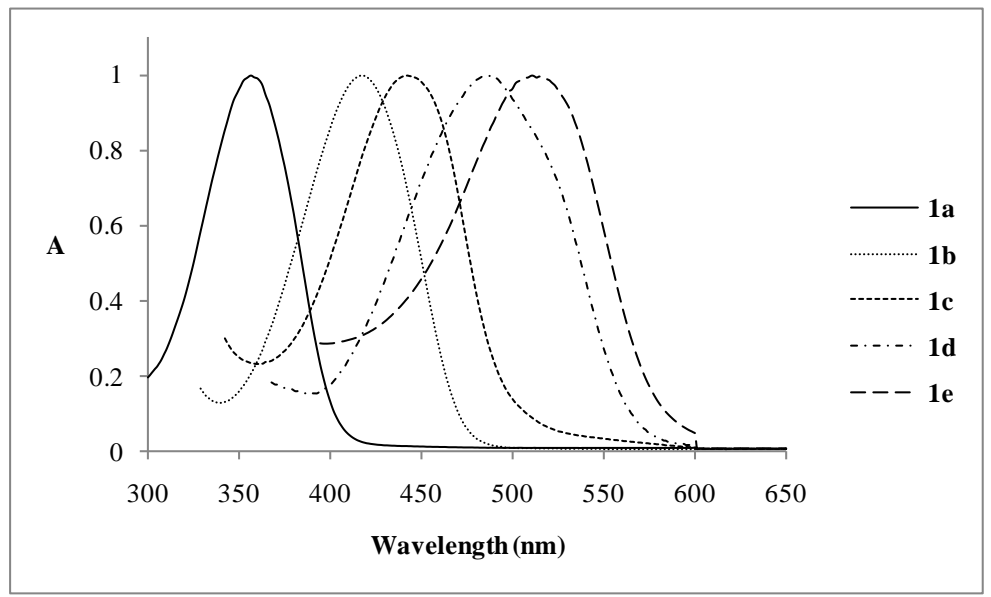

Figure 4. Comparative absorption spectra of 1a-e in dioxane at room temperature.

Previous studies have demonstrated that donor-acceptor substituted pyrroles exhibit a positive solvatochromism. ${ }^{8-12,19-20}$ In this case a moderate to large positive solvatochromism $\left(\Delta \nu_{\max }=488-981 \mathrm{~cm}^{-1}\right)$ was observed moving from diethyl ether to DMSO solutions for derivatives 1a-e. The UV-visible spectra of $\mathbf{1 b}$ in ethyl ether and in DMSO are given in figure 5. 


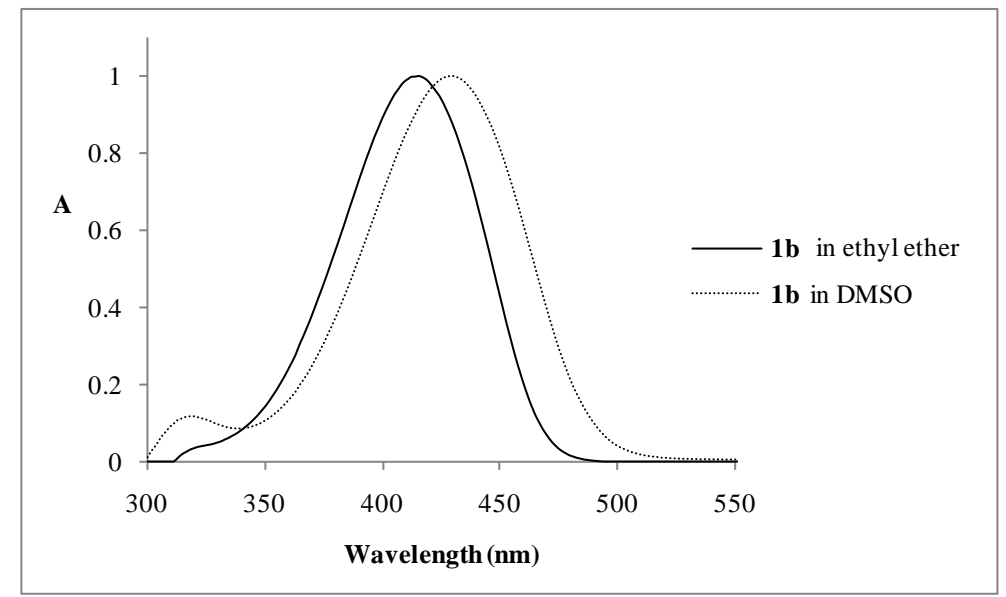

Figure 5. Comparative absorption spectra of $\mathbf{1 b}$ in ethyl ether and in DMSO at room temperature showing a large positive solvatochromism $\left(\Delta v_{\max }=786 \mathrm{~cm}^{-1}\right)$.

We have used the hyper-Rayleigh scattering (HRS) method $^{13-14}$ to measure the first hyperpolarizability $\beta$ of the compounds using the $1064 \mathrm{~nm}$ fundamental wavelength of a laser laser beam as described above. Dioxane was used as the solvent, and the $\beta$ values were measured against a reference solution of $p$-nitroaniline $(p N A)^{15-16}$ in order to obtain quantitative values, while particular care was taken to properly account for possible fluorescence of the dyes (see experimental section for more details). The static hyperpolarisability $\beta_{0}$ values were calculated using a very simple twolevel model neglecting damping. They are therefore only indicative and should be treated with caution (Table 3).

Table 3. Linear and nonlinear optical properties of chromophores $\mathbf{1}^{\mathrm{a}}$

\begin{tabular}{|ccccc|}
\hline Compounds & $\begin{array}{c}\lambda_{\max } \\
(\mathrm{nm})\end{array}$ & $\begin{array}{c}\varepsilon_{\max } \\
\left(\mathrm{M}^{-1} \mathrm{~cm}^{-1}\right)\end{array}$ & $\begin{array}{c}\beta^{\mathrm{b}} \\
\left(10^{-30} \mathrm{esu}\right)\end{array}$ & $\begin{array}{c}\beta_{0}^{\mathrm{c}} \\
\left(10^{-30} \mathrm{esu}\right)\end{array}$ \\
\hline $\mathbf{1 a}$ & 348 & 32,740 & 28 & $14 \pm 2$ \\
$\mathbf{1 b}$ & 419 & 39,180 & 92 & $30 \pm 3$ \\
$\mathbf{1 c}$ & 441 & 32,930 & - & - \\
$\mathbf{1 d}$ & 479 & 45,790 & 1048 & $158 \pm 5$ \\
$\mathbf{1 e}$ & 510 & 30,840 & 358 & $22 \pm 2$ \\
$\mathbf{p N A}$ & 352 & - & $16.9^{15-16}$ & 8.5 \\
\hline
\end{tabular}

${ }^{a}$ Experimental first hyperpolarizabilities $\beta$ and spectroscopic data measured in dioxane solutions.

${ }^{\mathrm{b}}$ All compounds are transparent at the $1064 \mathrm{~nm}$ fundamental wavelength.

${ }^{\mathrm{c}}$ Data corrected for resonance enhancement at $532 \mathrm{~nm}$ using the two-level model with $\beta_{0}=\beta\left[1-\left(\lambda_{\max } / 1064\right)^{2}\right]\left[1-\left(\lambda_{\max } / 532\right)^{2}\right]$; damping factors not included $1064 \mathrm{~nm}^{21-23}$

NLO chromophores $\mathbf{1 b}$ and 1d-e exhibit good to excellent molecular nonlinearities as their $\beta$ values are 5-62 times higher that of the well known $p$ NA molecule for an incident laser wavelength of $1064 \mathrm{~nm}$ (the corresponding $\beta_{0}$ values are 3 to 19 times higher than that of $p \mathrm{NA}$ ). From Table 3 it can be seen also that the static $\beta_{0}$ and the experimental $\beta$ values for compounds 1a-e follow the same ordering as deduced for the electron acceptor strength ordering found from 
the absorption band. Only one exception was observed in the sequence $\mathrm{CHO}<$ dicyanovinyl < rhodanine < thiobarbituric acid < 2-(3-oxo-2,3-dihydroinden-1-ylidene)malononitrile for the absorption band concerning compound 1e which gave lower $\beta_{0}$ and $\beta$ values than expected.

\subsection{Thermal stability}

Thermogravimetric analysis of the samples was carried out using a TGA instrument model Q500 from TA Instruments, under high purity nitrogen supplied at a constant $50 \mathrm{~mL} \mathrm{~min}^{-1}$ flow rate. All samples were subjected to a $20{ }^{\circ} \mathrm{C}$ min ${ }^{-1}$ heating rate and were characterized between 25 and $500{ }^{\circ} \mathrm{C}$. As shown in Table 1 compounds $1 \mathbf{b}-\mathbf{e}$ exhibit good to excellent thermal stability with decomposition temperatures varying from 239 to $277^{\circ} \mathrm{C}$. Compounds 1b (Fig. 6) and 1d functionalized with dicyanovinyl and thiobarbituric acid accepting groups are the more thermally stable push-pull derivatives, exhibiting higher decomposition temperatures $\left(\mathrm{T}_{d}=270-277^{\circ} \mathrm{C}\right)$. This property would benefit the practical applications of these chromophores when incorporated into actual optical devices.

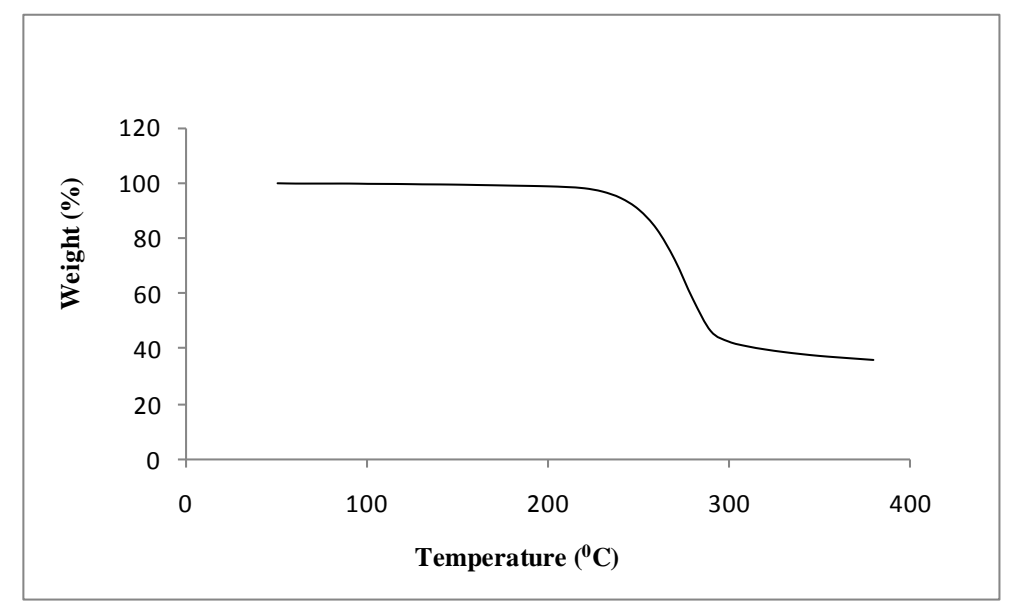

Figure 6. Thermal analysis data for compound $\mathbf{1 b}$ through TGA recorded under a nitrogen atmosphere, measured at a heating rate of $20{ }^{\circ} \mathrm{C} \mathrm{min}^{-1}$.

\section{SUMMARY}

In this work we report the synthesis, the redox properties and extensive physical characterization of several novel pushpull pyrrole derivatives. The static hyperpolarisability $\beta_{0}$ was calculated using the two level method and the experimental first hyperpolarizability $\beta$ were obtained using the hyper-Rayleigh scattering method. The experimental results obtained for theses derivatives showed that the electronic nature of the acceptor groups had significant influence on their thermal stability as well as their respective linear and nonlinear optical properties. In general when stronger electron acceptor groups are used in these chromophores, stronger hyperpolarizabilities are obtained. Finally, we verified that good optical nonlinearities are complemented by satisfactory thermal stability for chromophores $\mathbf{1 b}$ and $\mathbf{1 d - e}$ which makes them good candidates for NLO applications.

\section{ACKNOWLEDGEMENTS}

Thanks are due to the Fundação para a Ciência e Tecnologia (Portugal) and FEDER for financial support through the Centro de Química and Centro de Física-Universidade do Minho, Project PTDC/QUI/66251/2006 (FCOMP-01-0124FEDER-007429), Project PTDC/CTM/105597/2008 with funding from COMPETE/FEDER and a research grant to M. 
C. R. Castro (UMINHO/BI/142/2009). The NMR spectrometer Bruker Avance III 400 is part of the National NMR Network and was purchased within the framework of the National Program for Scientific Re-equipment, contract REDE/1517/RMN/2005 with funds from POCI 2010 (FEDER) and FCT.

\section{REFERENCES}

[1] He, G. S., Tan, L. S., Zheng, Q. and Prasad, P. N., "Multiphoton absorbing materials: Molecular designs, characterizations, and applications," Chem. Rev., 108, 1245-1330 (2008).

[2] Shi, Y. Zhang, Y. Q. C., Zhang, H., Bechtel, J. H., Dalton, L. R., Robinson, B. H. and Steier W. H., "Low (sub1-volt) halfwave voltage polymeric electro-optic modulators achieved by controlling chromophore shape," Science, 288, 119-122 (2000).

[3] Miller, R. D., Lee, V. Y. and Moylan, C. R., "Substituted azole derivatives as nonlinear-optical chromophores," Chem. Mater, 6, 1023-1032 (1994).

[4] Breitung, E. M., Shu, C.-F. and McMahon, R. J., "Thiazole and thiophene analogues of donor-acceptor stilbenes: molecular hyperpolarizabilities and structure-property relationships,” J. Am. Chem. Soc., 122, 1154-1160 (2000).

[5] Facchetti, A., Beverina, L., van der Boom, M. E., Dutta, E. G., Pagani, G. A. and Marks, T. J., "Strategies for electrooptic film fabrication. Influence of pyrrole-pyridine-based dibranched chromophore architecture on covalent self-assembly, thin-film microstructure, and nonlinear optical response," J. Am. Chem. Soc., 128, 2142-2153 (2006) and references cited.

[6] Davies, J. A., Elangovan, A., Sullivan, P. A., Olbricht, B. C., Bale, D. H., Ewy, T. R., Isborn, C. M., Eichinger, B. E., Robinson, B. H., Reid, P. J., Li, X. and Dalton, L. R., "Rational enhancement of second-order nonlinearity: bis-(4-methoxyphenyl)hetero-aryl-amino donor-based chromophores: design, synthesis, and electrooptic activity," J. Am. Chem. Soc., 130, 10565- 10575 (2008) and references cited.

[7] Abbotto, A., Beverina, L., Manfredi, N., Pagani, G. A., Archetti, G., Kuball, H. G., Wittenburg, C., Heck, J. and Holtmann, J., "Second-order nonlinear optical activity of dipolar chromophores based on pyrrole-hydrazono donor moieties," Chem.-A Eur. J., 15, 6175-6185 (2009) and references cited.

[8] Raposo, M. M. M., Sousa, A. M. R. C., Fonseca, A. M. C. and Kirsch, G., "Thienylpyrrole azo dyes: synthesis, solvatochromic and electrochemical properties," Tetrahedron, 61, 8249-8256 (2005).

[9] Raposo, M. M. M., Sousa, A. M. R. C., Kirsch, G., Ferreira, F., Belsley, M., Matos Gomes, E. and Fonseca, A. M. C., "Synthesis of tricyanovinyl-substituted thienylpyrroles and characterization of the solvatochromic, electrochemical and non-linear optical properties," Tetrahedron, 61, 11991-11998 (2005).

[10] Raposo, M. M. M., Sousa, A. M. R. C., Fonseca, A. M. C. and Kirsch, G., "Push-pull tricyanovinyl-substituted thienylpyrroles: synthesis, solvatochromic and electrochemical properties," Mater. Sci. Forum, 514-516, 98-102 (2006).

[11] Raposo, M. M. M., Sousa, A. M. R. C., Fonseca, A. M. C. and Kirsch, G., "Donor-acceptor substituted thienylpyrrole azo dyes: synthesis, solvatochromic and electrochemical properties," Mater. Sci. Forum, 514516, 103-107 (2006).

[12] Raposo, M. M. M. Sousa, A. M. R. C., Kirsch, G., Cardoso, P., Belsley, M., Matos Gomes, E. and Fonseca, A. M. C., "Synthesis and characterization of dicyanovinyl-substituted thienylpyrroles as new NLO-chromophores," Org. Lett., 8, 3681-3684 (2006).

[13] Clays, K. and Persoons, A., "Hiper-Rayleigh scattering in solution,” Rev. Sci. Instrum., 63, 3285-3289 (1992).

[14] Clays, K. and Persoons, A., "Hiper-Rayleigh scattering in solution," Phys. Rev. Lett., 66, 2980-2983 (1991).

[15] Teng, C. C. and Garito, A. F., "Dispersion of the nonlinear 2nd-order optical susceptibility of organic-systems," Phys. Rev. B, 28, 6766-6773 (1983).

[16] Stahelin, M, Burland, D. M. and Rice, J. E., "Solvent dependence of the 2nd-order hiperpolarizability in paranitroaniline," Chem. Phys. Lett., 191, 245-250 (1992).

[17] Yuan, M.-C., Chiu, M.-Y., Chiang, C.-M. and Wei K.-H., "Synthesis and characterization of pyrido[3,4b]pyrazine-based low-bandgap copolymers for bulk heterojunction solar cells," Macromolecules, 43, 6270-6277 (2010).

[18] Liang, Y., Feng, D., Wu, Y., Tsai, S.-T., Li, G., Ray, C. and Yu, L., "Highly efficient solar cell polymers developed via fine-tuning of structural and electronic properties, ”’ J. Am. Chem. Soc., 131, 7792-7799 (2009). 
[19] Batista, R. M. F., Costa, S. P. G., Malheiro, E. L., Belsley, M., Raposo, M. M. M., "Synthesis and characterization of new thienylpyrrolyl-benzothiazoles as efficient and thermally stable nonlinear optical chromophores," Tetrahedron, 63, 4258-4265 (2007).

[20] Raposo, M. M. M., Fonseca, A. M. C., Castro, M. C. R., Belsley, M., Cardoso, M. F. S., Carvalho, L. M. and Coelho, P. J., "Novel diazenes bearing pyrrole, thiophene and thiazole heterocycles as efficient photochromic and nonlinear optical (NLO) materials," Dyes Pigments, (2011), 10.1016/j.dyepig.2011.02.012.

[21] Oudar, J. L., "Optical nonlinearities of conjugated molecules - stilbene derivatives and highly polar aromatic compounds,” J. Chem. Phys., 67, 446-457 (1977).

[22] Oudar, J. L. and Chemla D. S., "Hiperpolarizabilities of nitrolanilines and their relations to excited-state dipolemoment," J. Chem. Phys., 66,2664-2668 (1977).

[23] Zyss, J. and Oudar, J. L., "Relations between microscopic and macroscopic lowes-order optical nonlinearities of molecular-crystals with one-dimensional or two-dimensional units," Phys. Rev. A, 26, 2016-1027 (1982). 